\title{
From solar energy to gamma-ray 'telescope'
}

Boston. Physicists in the United States and France are planning to convert equipment built to capture solar energy into a giant 'telescope' for detecting gamma rays and making other astronomical observations. The idea was first investigated in the $1970 \mathrm{~s}$, but abandoned as impractical.

Researchers working on the Solar Tower Atmospheric Cherenkov Experiment (STACEE) are gearing up to make astronomical observations at the Solar Two power station in Barstow, California, and at Sandia National Laboratory in New Mexico. Similar work is under way in the French Pyrenees at the Cherenkov Low Energy Sampling \& Timing Experiment (CELESTE) at the defunct Thémis solar power plant.

Both teams hope to make their first observations in the autumn of 1997. They say that the modified equipment could provide glimpses of an unexplored realm of the electromagnetic spectrum at a cost of less than US\$1 million.

The Solar Two power plant has 2,000 adjustable mirrors or 'heliostats', which can focus light onto a central tower. Scientists have studied the tracking ability of the heliostats, assessed the mirrors' optical qualities, and have measured the night sky background. They detected the flashes of blue Cherenkov light that result when

\section{NASA asks academy for space priorities}

Washington. The US National Aeronautics and Space Administration (NASA) has asked the National Academy of Sciences to assemble an expert group to come up with plans and priorities for space science. The group will present its results to vice-president Al Gore in early December, who will take the recommendations to a 'space summit' later that month at which the White House and Congress will try to agree on funding levels and priorities for the nation's space programme.

Wesley Huntress, head of science at NASA, told the agency's scientific advisory council this week that the interest of the Clinton administration in space science "has increased markedly" since the announcement this summer of possible Martian fossils. But the NASA/academy group will consider more than just plans for Mars. White House science adviser John Gibbons last week charged the experts to look at three broad topics: the Universe; planets; and the evolution of life on Earth and elsewhere.

Tony Reichhardit gamma rays penetrate the atmosphere.

This success was partly due to a suggestion from Tumay Tumer, a physicist at the University of California, Riverside, that a secondary optics system be used to reflect light from each heliostat to a separate photomultiplier detector, reducing background noise. The technique prompted some scientists to reconsider the solar farm approach.

At Sandia - which has 220 heliostats researchers set up a 3-metre-diameter secondary reflector in August, and demonstrated that they could align their 'telescope' to track stars and spot Cherenkov radiation. The next step will be to attempt to show that lower-energy gamma rays can be detected by increasing the mirror collector area.

Next year, the team hopes to use 50 mirrors at Solar Two to observe the Crab nebula and pulsar, which become visible in October. Rene Ong, the University of Chicago physicist who is leading the STACEE effort with Tumer, says: "That would be the first time light taken from a field of solar reflectors has produced an astronomical image."

The French team, led by Patrick Fleury and Eric Pare of the LPHNE Ecole Polytechnique, also plans to look at the Crab. The project was approved in July by the Institut National de Physique Nucléaire et de Physique des Particules, and has been awarded $\$ 600,000$.

Both groups intend to look at dozens of gamma-ray sources - pulsars, active galactic nuclei (AGN) and supernova remnants - identified by the EGRET instrument on the Compton Gamma Ray Observatory (GRO) using ranks of mirrors that were designed to focus the Sun's rays on a single point at the top of a tower.

The large mirror areas at the Solar Two and Thémis sites should allow examination of a segment of the gamma-ray spectrum, from 20 to $200 \mathrm{GeV}$, that has been inaccessible to space-borne and ground-based detectors.

Floyd Stecker, a theoretical astrophysicist at the NASA Goddard Space Flight Center in Maryland, says: "These new instruments will look at energies higher than EGRET observed, but lower than those seen from ground-based telescopes like the Whipple Observatory in Arizona."

Stecker hopes the projects will shed light on a class of AGNs called "blazars", which shoot high-energy gamma rays and jets of relativistic plasma towards Earth. "We'd like to know how blazars produce these gamma rays and what kind of new physics might be involved," he says.

If the research proves successful, the US and French groups plan to join forces for -

\section{Doubts cast on Chernobyl safety claims}

Moscow. Yuri Kostenko, Ukraine's minister of environment and nuclear security, became embroiled in new controversy last week when he announced at a press conference in Kiev that the 'fourth unit' of the Chernobyl atomic power station "could blow up any moment", following the detection of a ten-fold increase in radiation inside the sarcophagus.

Kostenko's comments came the day after returning from a meeting of the International Atomic Energy Agency in Vienna, at which he had reported on the state of the Chernobyl power station and stressed the need for Ukraine to receive the ECU118 million (US $\$ 147.5$ million) promised by the G7 countries to close the power station. "Any delay may make it impossible for Ukraine to fulfil this task before 2003," he had said a few days previously.

But Evgeny Velikhov, vice-president of the Russian Academy of Sciences, and director of the Kurchatov Institute, claimed that there was "nothing new" in the situation at Chernobyl "except for Kostenko's panic".

Similarly Georgy Kaurov, the head of information at the Russian Ministry of Atomic Energy, said that it was wrong to talk about a possible explosion at the power station and no data had been recorded on a rise in gamma radiation. Furthermore, the system for monitoring neutrons had been found unreliable during a previous visit by a commission from the ministry five years ago, and no improvements had since been made.

Those who claim that Kostenko's demands are efforts to raise more foreign aid say that their interpretation is confirmed by a chronology of recent events. On the evening of 16 September, several devices installed in the sarcophagus covering the fourth unit registered a rise in the flow of neutrons. Although in principle this could have indicated the initiation of a chain reaction, further measurements indicated that it was most likely the results of faults in the control system caused by heavy rain.

Initially Kiev had kept silent about the incident. But three days later Leonid Kuchma, the president of Ukraine, referred to the incident in discussions with French officials when he said that he was "deeply concerned" about the 200 tonnes of nuclear fuel buried under the power station's sarcophagus. Viktor Baryakhtar, vice-president of the Ukrainian Academy of Sciences, and a nuclear adviser to Kuchma, said that the possibility of a small explosion at Chernobyl "cannot be totally ignored". 


\section{US increases health funds but ducks AIDS allocation}

\section{IMAGE UNAVAILABLE FOR COPYRIGHT REASONS}

Cause for reflection: the French Thémis plant could be used to detect gamma rays.

- a big experiment, probably at Solar Two. With its 2,000 mirrors, each with an area of 40 square metres, Solar Two has the potential to be "the most powerful and sensitive gamma-ray observatory", says Ong.

But not everyone agrees. Trevor Weekes, head of the gamma-ray astronomy group at the Whipple Observatory, believes that makeshift facilities at solar farms cannot be substituted for fully fledged observatories. $\mathrm{He}$ says that the long-term monitoring needed to characterize gamma-ray sources can be done only with a dedicated telescope.

"The solar arrays in Barstow and Thémis have sufficient mirror area to extend ground-based gamma ray detection techniques to lower energies. However, if one were to design an atmospheric Cherenkov telescope from scratch, one would never design the mirrors in this configuration, nor is it likely that one would locate the telescope at these sites."

At best, he says, solar farm instruments can "fill the gap temporarily" before the next-generation space observatory (such as the yet-to-be-approved GLAST telescope ) and ground-based observatory (such as the proposed \$10-million ATHENA project at Whipple) become available.

Ong replies: "It could be 10 years before either project comes to fruition, and some interesting science might be done in the meantime." A participant in GLAST, Ong is as anxious as anyone to see the mission fly. But he says the mirrors on the proposed space observatory would not be big enough to detect weak sources. And ATHENA would focus on higher-energy gamma rays than STACEE and CELESTE.

Ong agrees with Weekes that a solar farm 'telescope' will fall short of the "ultimate" gamma-ray observatory. But to build such a mirror from scratch would cost $\$ 100$ million.

Steve Nadis
Washington. The budget for the National Institutes of Health (NIH) in the 1997 fiscal year, which began on 1 October, will - as widely anticipated - be 6.9 per cent higher than the 1996 budget, under a bill passed by the US Congress and signed by President Clinton late on Monday. But it has sparked controversy over its failure to specify how much should be spent on AIDS research.

The NIH budget, which will total $\$ 12.7$ billion, includes $\$ 90$ million to begin the construction of the planned Clinical Research Center on the NIH campus. "I'm extremely pleased," said John Porter (Republican, Illinois), chairman of the House labor, health and human services and education appropriations subcommittee, who authored the 6.9 per cent funding increase and persuaded colleagues to adopt it over the more modest 4.1 per cent increase proposed in the Senate.

The budget law also includes a new compromise on the status of the NIH's politically embattled Office of AIDS Research (OAR). Under this, the office will be allowed to determine how much money is spent on AIDS, to allocate this between the NIH's 24 institutes, divisions and centres, and to shift funds between institutes during the year, within limits. The power to shift this money - up to $\$ 45$ million - is a new one, aiming to allow the OAR to respond to changing research developments.

But, reflecting the fact that some House Republicans have opposed earmarking money for AIDS, the measure does not specify how much of the NIH budget should be spent on AIDS research - although this was required by the 1993 law that established the current powers of the OAR. Instead, it says merely that Harold Varmus, the director of NIH, and William Paul, the director of OAR, will jointly agree a figure.

A report accompanying the budget law sets this figure at $\$ 1.5$ billion, a 6.6 per cent increase over 1996. "This simply gives [Paul] appropriation authority, without providing a line item that would be diseasespecific," said Porter. "It preserves our very strong intent that science determine the allocation of funding for research, and not politics."

Speaking after house passage of the bill, Paul said the NIH would have preferred a single-line item in the budget, known as a 'consolidated appropriation'. But the bill as written nonetheless grants the OAR much of the same flexibility as before, "and in some respects goes beyond" former limits, he says, referring to the power to transfer funds between institutes.

But AIDS activists, the Clinton administration and some scientists called the compromise a partisan political gambit that ignores the wishes of the scientific community. "The scientists want [the strongest possible OAR]. That's what's so galling about Porter's attitude," said one AIDS scientist.

Gregg Gonsalves, policy director with Treatment Action Group, a national organization that lobbies for AIDS research, said the deal was made "in the best interest of right wing politics". A Clinton administration official who follows the issue admits that "our absolute preference [was] to have the full authority of the OAR", but adds that "we continued to run into a brick wall in the House".

OAR supporters also worry that, if voters return a republican congress in November's elections, the compromise could hurt their position in imminent negotiations to renew the 1993 law that established the OAR as overseer of NIH AIDS research.

Nevertheless the compromise is the closest thing yet to a truce in a political battle which has beset the OAR since 1993, when it was first put in full charge of the AIDS research portfolio. According to one Congressional staff member, neither side can complain too loudly about the arrangement, because it does two things. It allows Porter to say there is no earmark for AIDS in the 1997 spending bill, and it allows Paul to control AIDS funds.

Congressional conservatives have protested that the OAR's control over nearly 12 per cent of the NIH's budget puts AIDS on a pedestal not granted other diseases, at the urging of AIDS activists. But the office is also backed by many scientists, including Nobel laureates David Baltimore of the Massachusetts Institute of Technology, and Torsten Weisel, president of Rockefeller University.

The latter were among more than 350 scientists who signed letters this year to Congressional leaders urging that the OAR keep its full authority. Last March, a committee of 118 experts headed by Arnold Levine, a molecular biologist at Princeton University, recommended that the office should retain its full power over the AIDS purse strings $-\$ 1.4$ billion in the 1996 fiscal year.

This summer, the House passed a 1997 spending bill which restricted the OAR's authority, as did the republican-authored law which funded the OAR in the 1996 fiscal year. The parallel Senate bill did not restrict the OAR, but it did not reach a vote. The new bill gives OAR the flexibility to transfer between institutes during the year up to three per cent of a given institute's AIDS budget.

Meredith Wadman 